\title{
Development of Measuring Apparatus for Contact Wire Wear Using Sodium Vapor Lamps
}

\author{
Hiroki NAGASAWA \\ Manager, Research \& Development Promotion Div. \\ Takahiro FUKUTANI \\ Researcher, \\ Current Collection Maintenance, Power Supply Technology Div.
}

For the maintenance of overhead contact line, it is important to know the exact state of contact wire wear in electric railways. A new type of measuring apparatus has been developed, which is sufficiently small to be installed on the roof of commercial car. The apparatus has an optical system composed of sodium vapor lamps and CCD line sensor cameras with optical filters. This apparatus detects the width of wear surface of wire, and calculates the residual height from the width. The measuring frequency of the cameras is $1 \mathrm{kHz}$. The new apparatus has been tested in a laboratory and in the field by using an inspection car. The results show that it can be used at the speed of $100 \mathrm{~km} / \mathrm{h}$ in daytime at a standard deviation of measuring error of $0.3 \mathrm{~mm}$.

Keywords : contact wire, wear, measurement, sodium vapor lamp, CCD camera

\section{Introduction}

For the maintenance of overhead contact line, it is important to know the exact state of contact wire wear in electric railways. Therefore, there are several types of measuring equipment which are used at night or in daytime $^{1-4)}$.

However, the daytime apparatus is too large to install on a commercial car. Therefore, a new type of measuring apparatus has been developed, which is sufficiently small to be installed on the roof of commercial car.

The apparatus has an optical system composed of sodium vapor lamps and CCD line sensor cameras with optical filters. The new apparatus has been tested in a laboratory and in the field by using an inspection car. The results show that it can be used at the speed of 100 $\mathrm{km} / \mathrm{h}$ in daytime at a standard deviation of measuring error of $0.3 \mathrm{~mm}$.

\section{Method of measurement}

\subsection{Required performance}

The measuring apparatus should have the following performance.

(1) It can be used in daytime.

(2) Measuring frequency is over $500 \mathrm{~Hz}$ to make the measuring pitch $70 \mathrm{~mm}$ in $130 \mathrm{~km} / \mathrm{h}$ running.

(3) Measuring range for vertical height of the contact wire is $1 \mathrm{~m}$.

(4) Measuring range for horizontal deviation is $\pm 350 \mathrm{~mm}$.

(5) It can measure maximum four wires simultaneously.

\subsection{Method of measurement}

The cross section of the contact wire used in Japan is round with two grooves as shown in Fig. 1. The wear surface of wire becomes a flat plane when worn by the sliding of pantograph.

For the accuracy of measuring, the residual height of wire should be measured directly. But it is difficult when the inspection car runs at high speed. Therefore, a method to optically measure the width of wear surface has been adopted. The residual height of contact wire is calculated from the width of wear surface.

\subsection{Measuring devices}

(1) Lamps used to illuminate the contact wire

Low-pressure sodium vapor lamps are used to illuminate the wear surface of contact wire for the following reasons.

First, it radiates a single wavelength light at high efficiency. Second, the tubular shape of the lamp covers the entire deviation range of wire. Third, the lamp will recover the normal luminance level quickly when an instantaneous power interruption occurs.

(2) Cameras for measuring the width of wear surface

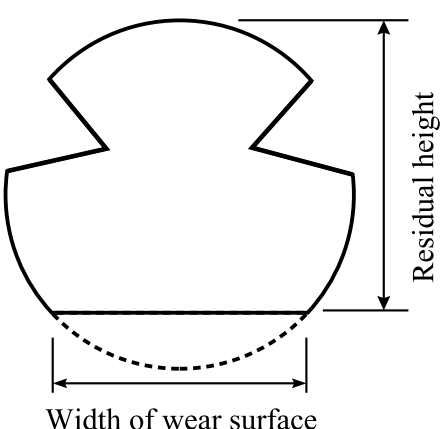

Fig. 1 Cross section of contact wire. 
CCD line sensor cameras are used to detect the light reflected from the wear surface of contact wire. It is suitable to cover the deviation range of contact wire as the CCD camera electrically scans the elements (i.e. pixels).

When two cameras, each having 5000 pixels in line, are used to measure the width of wire in horizontal deviation range of $\pm 350 \mathrm{~mm}$, the theoretical accuracy of the apparatus is $0.07 \mathrm{~mm}$.

\subsection{Possibility for daytime measurement}

For daytime measurement, the luminance of the wear surface of contact wire shall be higher than that of sky light.

When the wear surface of contact wire is assumed to be a perfect diffuser, and the illuminance of the wear surface is denoted by $E[\mathrm{~lx}]$, the output level of a CCD camera is calculated as follows.

$$
p_{t}=k E \rho \tau_{t} l g / \pi
$$

where $p_{t}$ is the output level of the CCD camera [V]; $k$ is a constant; $\rho$ is the reflectance of the wear surface; $\tau_{t}$ is the transmittance of the optical filter; $l$ is the loss in the lenses and $g$ is the efficiency of the CCD $\left[\mathrm{V} \mathrm{cd}^{-1} \mathrm{~m}^{2}\right]$.

For the other side, the output level of the skylight is calculated as follows.

$$
p_{s}=k L \tau_{s} l g
$$

where $p_{s}$ is the output level of the CCD camera [V]; $L$ is the luminance of skylight and $\tau_{s}$ is the transmittance of the optical filter for skylight.

Therefore, the rate of output level between the wear surface and skylight is as follows.

$$
p_{t} / p_{s}=E \rho \tau_{t} /\left(\pi L \tau_{s}\right)
$$

When $\tau_{t}$ is 0.7 and $\tau_{s}$ is 0.01 for the rate $p_{t} / p_{s}>2$, the following condition must be satisfied.

$$
E \rho>0.09 L
$$

When $L$ is $8000\left[\mathrm{~cd} / \mathrm{m}^{2}\right]$ and $\rho$ is $0.3, E$ should be higher than 2400 [lx]. This condition can be satisfied.

\section{Composition of the apparatus}

The apparatus is composed of three units which are, optical unit, control unit and processing unit. The optical unit is installed on the roof of the measuring car.

\subsection{The composition of optical unit}

The composition of optical unit is shown in Fig. 2. It has three $180 \mathrm{~W}$ low pressure sodium vapor lamps and $70 \mathrm{kHz}$ power sources. Distribution of the illuminance is shown in Fig. 3. The illuminance is high enough for measurement in daytime.

The light reflected from the wear surface is detected by the CCD cameras through several mirrors.

As the vertical height of the contact wire from the rail changes as the measuring car runs, the positions of mirrors are controlled by using the signal of contact wire height which is measured by a pantograph.

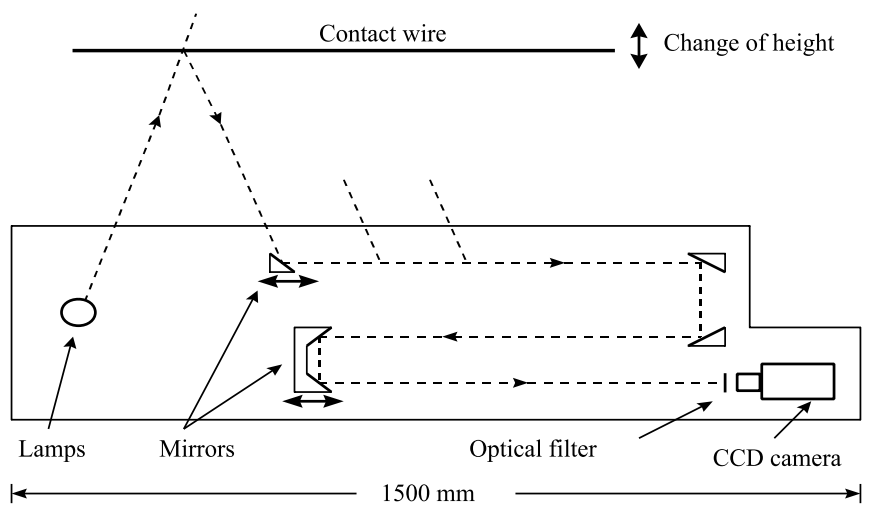

Fig. 2 Composition of optical unit.

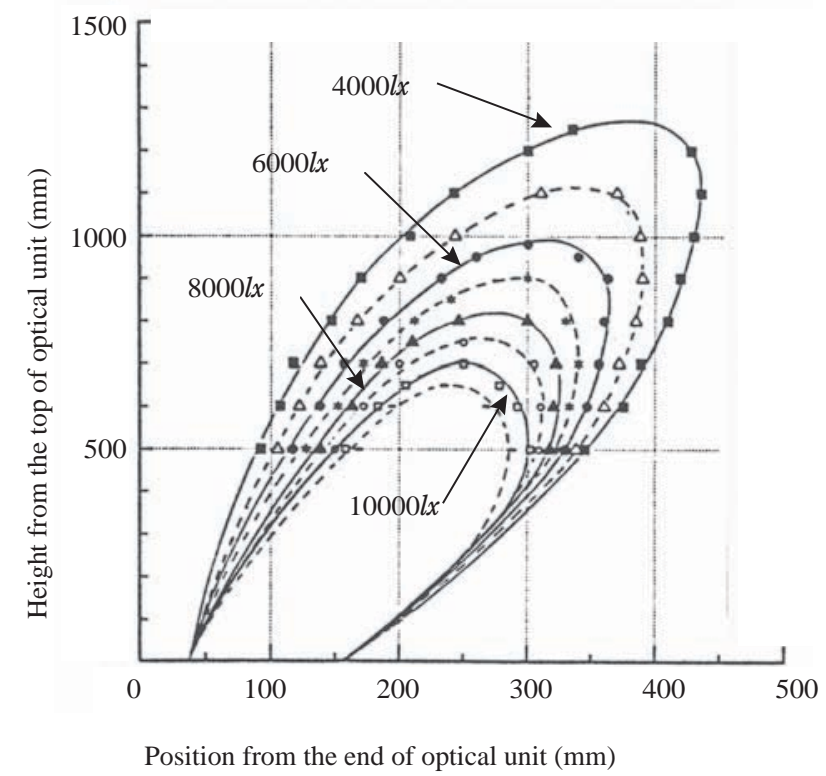

Fig. 3 Distribution of illuminance on contact wire.

\subsection{Compositions of control unit and processing unit}

The control unit has switches, connectors and alarm indicators. The processing unit is a personal computer in which signal processing boards are installed. Fig. 4 shows the flowchart of signal processing.

\section{Field tests}

The apparatus was installed on an inspection car and tested on the Tokyu corporation lines. Fig. 5 shows the optical unit mounted on the roof of the car.

Fig. 6 (a) is an example of a chart of a measurement obtained by the apparatus at the speed of about $100 \mathrm{~km} /$ h. Fig. 6 (b) is a chart of measurement in the same area obtained by a roller type device at the speed of about 4 $\mathrm{km} / \mathrm{h}$. The two waves are almost same in shape.

Fig. 7 shows the distribution of measuring errors at local wear points. The standard deviation of the measuring error is about $0.3 \mathrm{~mm}$. 


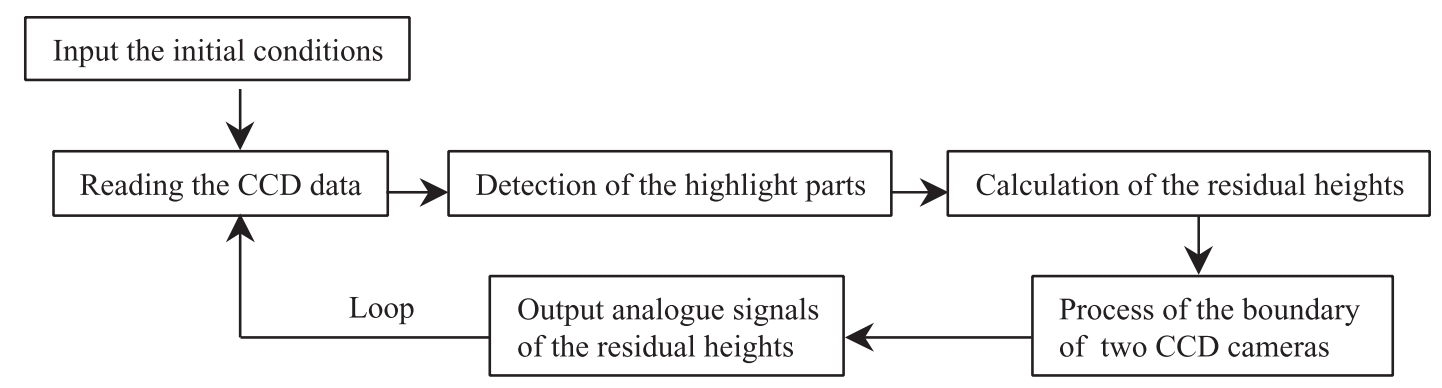

Fig. 4 Flow of signal processing.

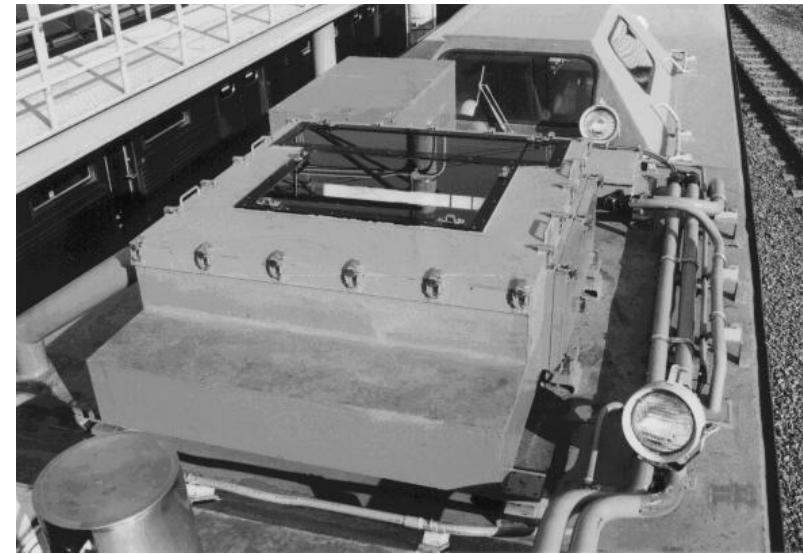

Fig. 5 Appearance of the optical unit mounted on the roof of the inspection car.

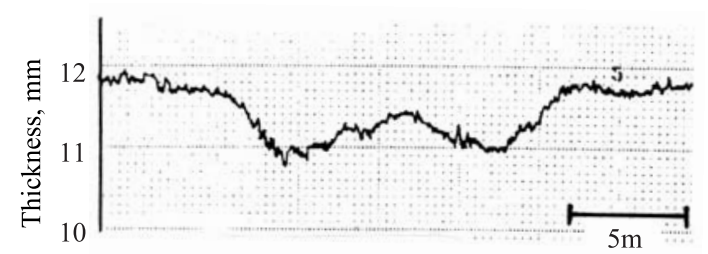

a) Data measured by the apparatus (At about $100 \mathrm{~km} / \mathrm{h}$ )

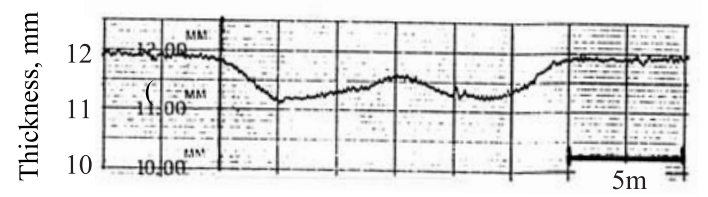

b) Data measured by the roller type device (At about $4 \mathrm{~km} / \mathrm{h}$ )

Fig. 6 Data measured by the apparatus and roller type equipment.

\section{Conclusions}

A measuring apparatus for contact wire wear using sodium vapor lamps and CCD cameras is developed and tested in a laboratory and in the field. The results of the tests are as follows.

(1) Three $180 \mathrm{~W}$ lamps give a sufficient illuminance for measurement in daytime.

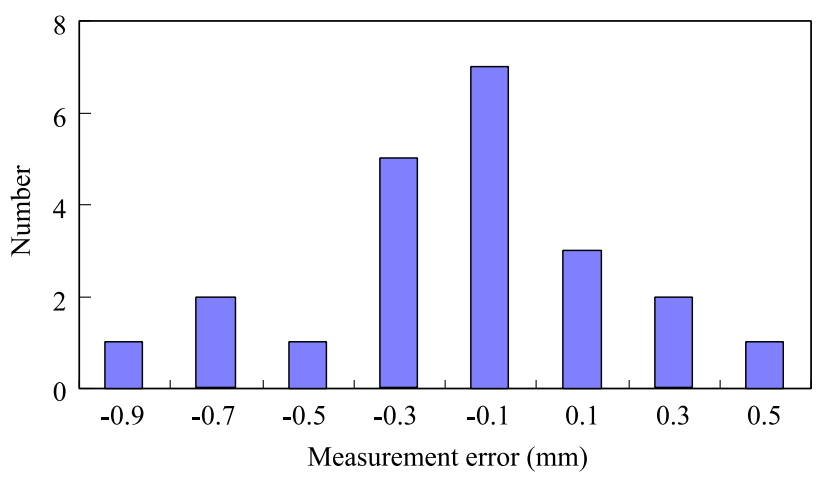

Fig. 7 Distribution of measuring errors.

(2) The measuring pitch is over $500 \mathrm{~Hz}$ when the apparatus is controlled by a personal computer.

(3) Measurement is possible at the speed of $100 \mathrm{~km} / \mathrm{h}$. The standard deviation of measuring errors is $0.3 \mathrm{~mm}$.

\section{Acknowledgements}

This development was supported by the Ministry of Transport of Japan. Furthermore, the field tests were carried out in cooperation with Tokyu corporation and JR groups. The authors wish to express sincere gratitude to the Ministry and those who kindly extended cooperation to this study.

\section{References}

1) J.M.Van Gigch, et al.: "The Contact Wire ThicknessMeasuring System (ATON) of the Netherlands Railways", Rail International, pp.20-31, April 1991

2) K.Horiki, et al.: "Measurement of Contact Wire Wear on Daytime Using Laser", Report of Railway Technical Research Inst., No.1085, 1978

3) H.Yoshida, F.Michishita: "Development of Measuring Equipment for Contact Wire Wear using CCD Sensor (Rp.3)", Technical Review of Kintetsu Research Inst., Vol.22, pp.79-87, 1991

4) R.Muller: "Contact wire wear measurement devices A system comparison", WCRR, No.1085, 1997 